to be preventable. In breech presentation when the obstetrician has any suspicion of disproportion a caesarean section is less of a risk than exposing the baby to a "trial labour." During vaginal breech delivery-in the absence of disproportion-the obstetrician must guard against excessive pressure on the suboccipital region of the after-coming head either by his own fingers or against the mother's symphysis pubis. This is where experience, manipulative skill, and, above all, gentleness count for so much.

1 Yates, P O, Archives of Disease in Childhood, 1959, 34, 436.

2 Yates, P O, Spastics Quarterly, 1962, 11 (3), 15.

${ }^{3}$ Ralis, Z A, Archives of Disease in Childhood, 1975, 50, 4

+ Dunn, P M, in Perinatal Medicine. Fifth European Congress of Perinatal Medicine, ed G Rooth and L E Bratteby, p 56. Stockholm, Almqvist and Wiksell International, 1976.

5 Wigglesworth, J S, and Husemeyer, R P, British fournal of Obstetrics and Gynaecology, 1977, 84, 684 .

${ }^{6}$ Hemsath, F A, American fournal of Obstetrics and Gynecology, 1934, 27, 194.

' Neligan, G A, Prudham, D, and Steiner, H, The Formative Years. Birth, Family and Development in Newcastle upon Tyne, p 25. London, Oxford University Press, 1974.

\section{Dietary amenorrhoea}

It has been known for centuries ${ }^{1}$ that extreme degrees of fasting will cause amenorrhoea: indeed, one explanation of anorexia nervosa is that girls with the disorder are driven by a desire to suppress their periods and to return to the prepubertal state. ${ }^{2}$ More recently minor degrees of weight loss, unassociated with psychological problems, have become recognised as a cause of interrupted menstruation ${ }^{3}-a$ phenomenon that has been called nutritional ${ }^{4}$ or dietary ${ }^{5}$ amenorrhoea.

Dietary restriction is, in fact, a surprisingly common cause of amenorrhoea. In a series of 170 amenorrhoeic patients studied at St Mary's Hospital, London, ${ }^{6}$ self-imposed weight loss was the most common single cause, being responsible for 39 cases: 24 of these women had true anorexia nervosa, but in the remaining 15 the criteria for the diagnosis ${ }^{7}$ were not satisfied. A report from Glasgow ${ }^{5}$ claims that dietary amenorrhoea, short of frank anorexia nervosa, accounted for $14^{\circ}{ }_{0}$ of all new attendances at a gynaecological endocrinology clinic and for $25^{\circ}$ of cases of amenorrhoea or gross menstrual irregularity.

The condition is found most frequently in young women, the mean age in most series ${ }^{4-6}$ being around 21 . Unlike patients with anorexia nervosa, women with dietary amenorrhoea often complain of loss of appetite and have an appropriate perception of their body image; their weight loss may sometimes be the result of physical disease or depression. The two conditions, however, are seen by some authorities as parts of a continuum rather than as separate diseases.

Why should menstruation cease when a woman's weight begins to fall? One suggestion is that every woman has a critical weight below which menstruation will not occur: Frisch and McArthur believe that this weight can be calculated from a woman's height, ${ }^{8}$ and they offer the theory that ovulatory cycles occur only in women with large enough fat stores to sustain them through pregnancy. This idea is not supported by the data of the St Mary's group, ${ }^{6}$ who concluded that it was loss of weight rather than absolute weight that determined amenorrhoea.

The exact nature of the endocrine abnormality in patients with dietary amenorrhoea is not yet certain. They have low serum concentrations of oestradiol and luteinising hormone (LH) but normal amounts of other hormones, including prolactin. ${ }^{6}$ Patients with true anorexia nervosa have a substantially impaired $\mathrm{LH}$ response to luteinising-hormonereleasing hormone $(\mathrm{LHRH})^{9}$ and abnormalities of thyroid function. ${ }^{5}$ Patients with dietary amenorrhoea also have an impairment of the $\mathrm{LH}$ response to LHRH as well as of the growth hormone response to hypoglycaemia, ${ }^{10}$ indicating an abnormality in either the pituitary or the hypothalamus. Others have reported that the $\mathrm{LH}$ response is of normal size but is delayed, ${ }^{11}$ a finding that suggests a hypothalamic disturbance. Thyroid function tests have given normal results in these patients, ${ }^{6}{ }^{10}$ but the Glasgow group ${ }^{5}$ found low basal serum concentrations of thyroid hormones in their patients and in three of the four patients tested the response to thyrotrophin-releasing factor was prolonged, again indicating a hypothalamic disturbance. Just how a decrease in body weight can so affect the function of the hypothalamus is not known.

The diagnosis of dietary amenorrhoea should be made only after careful investigation to exclude other causes of secondary amenorrhoea, and in particular pituitary tumours. ${ }^{12}$ Once the diagnosis is made, however, treatment is not difficult. Usually these patients (unlike those with true anorexia nervosa) are fairly easily encouraged to replace some of the weight they have lost. ${ }^{4}$ As patients approach their ideal weight they mostly resume menstruation associated with ovulatory cycles $^{6}$ generally within six months, but the process may take nearly a year. ${ }^{4}$ Recognition of this cause of secondary amenorrhoea may therefore spare some women from undergoing more elaborate treatment for their infertility.

\footnotetext{
${ }^{1}$ Morgan. H G, British Medical fournal, 1977, 2, 1652.

British Medical Fournal, 1978, 1, 5.

${ }^{3}$ Shearman, R P, American fournal of Obstetrics and Gynecology, 1969, 103, 444.

${ }^{4}$ McArthur, J W, et al, Mayo Clinic Proceedings, 1976, 51, 607.

5 Thomson, J E, Baird, S G, and Thomson, J A, Clinical Endocrinology 1977, 7, 383.

${ }^{6}$ Knuth, U A, Hull, M G R, and Jacobs, H S, British Fournal of Obstetrics and Gynaecology, 1977, 84, 801 .

${ }^{7}$ Feighner, J P, et al, Archives of General Psychiatry, 1972, 26, 57.

${ }^{8}$ Frisch, R E, and McArthur, J W, Science, 1974, 185, 949.

${ }^{9}$ Sherman, B M, Halmi, K A, and Zamudio, R, fournal of Clinical Endocrinology and Metabolism, 1975, 41, 135.

10 Hirvonen, E, et al, Acta Endocrinologica, 1977, 84, 225.

1 Vigersky, R A, et al, Fournal of Clinical Endocrinology and Metabolism, $1976,43,893$.

12 Shearman, R P, and Fraser, I S, Lancet, 1977, 1, 1195.
}

\section{The price of survival in childhood leukaemia}

Now that many children with lymphoblastic leukaemia achieve prolonged remission and perhaps cure attention is being focused on the quality of their survival. It is reassuring to learn from the Memphis group that most children who have completed treatment are well and have resumed normal activities. ${ }^{1}$ But what are the prospects for growth, development, and reproductive function in these children? How far does treatment carry a risk of damage to the liver, lungs, or other organs? Does cranial irradiation, especially in the young child, impair intellectual development? The answers to some of these questions are beginning to emerge.

Some retardation of growth may result from the intensive chemotherapy and the cranial and sometimes spinal radiotherapy given to prevent leukaemic infiltration of the central 